Journal of Advanced Research in Fluid Mechanics and Thermal Sciences

\title{
Effect Of $3 \%$ Molybdenum (Mo) Nanoparticles on The Melting, Microstructure and Hardness Properties of As- Reflowed Low Mass Sn-58Bi (SB) Solder Alloy
}

\author{
Amares Singh ${ }^{1,2,}{ }^{*}$, Rajkumar Durairaj ${ }^{2}$, Kuan Seng How ${ }^{2}$ \\ 1 Centre for Advanced Materials and Intelligent Manufacturing, Faculty of Engineering and Built Environment, SEGi University No. 9, Jalan \\ Teknologi, Taman Sains Selangor, Kota Damansara PJU 5, 47810 Petaling Jaya, Selangor, Malaysia \\ 2 Lee Kong Chian Faculty of Engineering and Science, Universiti Tunku Abdul Rahman, Jalan Sungai Long, Bandar Sungai Long, 43000 Kajang, \\ Selangor, Malaysia
}

\section{ARTICLE INFO}

\section{Article history:}

Received 5 June 2020

Received in revised form 15 October 2020

Accepted 20 October 2020

Available online 4 November 2020

\section{ABSTRACT}

The Sn-58Bi (SB) lead free solder alloy tested in this research with addition of $3 \%$ Molybdenum (Mo) nanoparticles equivalent to $0.6 \mathrm{~g}$ mass to analyse the influences in the thermal, microstructure and microhardness. Elevation of $3.8^{\circ} \mathrm{C}$ was observed from the Differential Scanning Calorimetry (DSC) for the 3\% Mo nanoparticles added SB solder alloy compared to the bare $\mathrm{Sn}-58 \mathrm{Bi}(\mathrm{SB})$ solder alloy that has a melting temperature of $142.25^{\circ} \mathrm{C}$. The microstructures of the reinforced SB solder alloy were refined with closer lamellar structures of $\beta$-Sn and $\mathrm{Bi}$ phases compared to the unreinforced SB solder. The SEM/EDX and X-ray Diffraction (XRD) results validate the presence of the $3 \%$ Mo nanoparticles in the SB solder. Mechanical properties by means of Vickers microhardness of the Mo reinforced solder alloy showed an increment in hardness value by $2 \%$ compared to the bare SB solder alloy. The presence of $3 \%$ Mo as discrete particles (dispersion strengthening) contributes to the increase on the hardness value. The introduction of $3 \% \mathrm{Mo}$ in to the SB solder alloy resulted in increase in the hardness due to the refinement of the microstructure and at the same time allows low temperature soldering in the electronic packaging industry.

Keywords:

SnBi solder alloy; low melting temperature; nanoparticles reinforcement; microstructure; mechanical properties

\section{Introduction}

In the soldering technology, the efficiency of a solder alloy is determined by the alloying process, such as $\mathrm{Sn}-\mathrm{Pb}, \mathrm{Sn}-\mathrm{Bi}$ and $\mathrm{Sn}-\mathrm{Ag}-\mathrm{Cu}$ solders which are a mixture of one or more elements to the base materials Tin (Sn). The alloying elements will undergo diffusion process and forms intermetallic compounds or just present as a solid solution in the solder alloy depending on the solubility and

\footnotetext{
* Corresponding author.

E-mail address: amaressinghgill@segi.edu.my
}

https://doi.org/10.37934/arfmts.77.1.6987 
reactivity of these elements [77]. This alloying process boosts the performance of a solder alloy by enhancing its properties by lowering the melting temperature (e.g. $\mathrm{Sn}-\mathrm{Pb}, \mathrm{Sn}-\mathrm{Bi}$ ), producing high shear strength (e.g. Sn-Zn-Bi) and enabling long-term reliability (e.g. Sn-Ag-Cu) due to better joint property. However, it could also contribute to some negative effect on the properties $[67,74,80]$. Lead free solder alloy are vastly investigated and the commonly claimed potential candidate is the $\mathrm{Sn}-\mathrm{Ag}-\mathrm{Cu}$ (SAC) solder alloys [19]. The noticeable properties of this solder alloy are its high melting temperatures $\left(217^{\circ} \mathrm{C}\right)$ that can cause damage to other components in the PCB during soldering. In the same context, the high temperature could cause a high coefficient of thermal expansion (CTE) that may deteriorate the wettability and cause tearing of the solder alloy from the copper in the PCB board. Low temperature soldering is key to sustain to sustain other components from further damage due to high temperature exposure, and also contributes to further enhancement in the wetting and interfacial properties [2]. Nanoparticles reinforcement are debated to provide better mechanical integrity to a lead free solder in terms of shear strength and hardness and these context of the study is the most recent problem statement in this area of research [54]. Nanoparticles can act as separate or discrete particles (oxide and high temperature nanoparticles) or even involve in diffusion and affect the properties by an alloying manner (metals elements) [25,87]. Research by Yang et al., [89] focused on the SnBi solder alloy with the additions of the Ni-coated carbon nanotubes (CNT) that shows an increase in the tensile strength up to $0.05 \% \mathrm{Ni}$-CNT content, but later reduced with added content of $0.1 \%$ and higher. The $0.05 \%$ additions produced the ultimate tensile strength of $63 \mathrm{MPa}$, which dropped to $61 \mathrm{MPa}$ with $0.1 \%$ content. In the same study, the surface fracture trend of shifted from ductile to brittle mode observed. The drop in the tensile strength was attributed by the presence of many $\mathrm{Ni}-\mathrm{CNT}$, which forms cluster and leave gaps/pores that acts as the stress concentrator. Ani et al., [11] also provided similar observation with the additions of $\mathrm{TiO} 2$ in the SnAgCu solder alloy. In another study, SiO2 nanoparticles were added to Sn0.7Cu solder alloy where there was an increment in tensile stress $(43.4 \mathrm{MPa})$ for $1.5 \mathrm{wt} \%$ additions which was $25 \%$ higher than

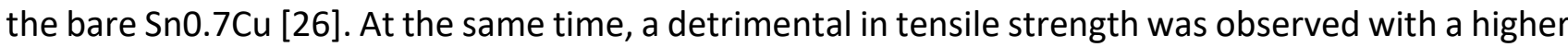
concentration of $\mathrm{SiO} 2$ of more than $1.5 \mathrm{wt} \%$. The initial boost in the tensile strength is because the $\mathrm{SiO} 2$ resists plastic deformation and produces an Orowan strengthening effect. These findings were also discovered in the research of Ding et al., [20] with additions of Al2O3 nanoparticles in the Sn9Zn solder. The microstructure of the Sn3.0Ag0.5Cu solder added with TiC nanoparticles was refined with smaller grain size and presence of more IMC compounds. These findings were key factors to the increment of hardness as found in the studies by Billah et al., [13] who incorporated Ni particles into Sn8Zn3Bi solder alloy. Investigations also show that the additions of nanoparticles could elevate the initial melting point of the mother solder alloy due to dissolution of the nanoparticles and the occurrence of melt undercooling before solidification. The proclamation was aligned to the research

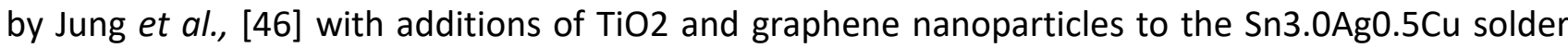
alloy and likewise reported by Zhu et al., [95] (addition of carbon nanotube to SAC solder) and Chellvarajo et al., [17] (additions of Fe2NiO4 to SAC solder). In contrast, Xing et al., [84] obtained a reverse trend of decrease in the melting temperature with additions of the Al2O3 nanoparticles to the Sn9Zn solder alloy. Thus, the trend seems to focus on the SAC solder alloy system but few have argued on the reinforcement of the nanoparticles into a low melting solder alloy, such as the $\mathrm{SnBi}$ solder alloy. This paper investigates the additions of 3\% Mo nanoparticles in the SnBi solder alloy and its effects on the melting, hardness and microstructure properties. 


\section{Preparation of Solder Alloy and Testing Setups}

The Sn-58Bi (SB) solder alloy was prepared from Tin (Sn) (99.9\% pure, Sigma Aldrich) and Bismuth (Bi) (99.9\% pure, Sigma Aldrich) whereby both the elements were melted at $600^{\circ} \mathrm{C}$ for 1 hour (soaking time) in a furnace. The Mo (Sigma Aldrich) nanoparticles (Figure 1) was also weighed accordingly to $3 \%$ from the total weight of SB and inserted together at this point. The 3\% Mo + SB nanoparticles solder alloy were further mechanically stirred at $350^{\circ} \mathrm{C}$ for 15 minutes to achieve homogeneity. The density of the SB solder alloy is $8.785 \mathrm{~g} / \mathrm{cm}^{3}$ and the density of Mo nanoparticles is $10.2 \mathrm{~g} / \mathrm{cm}^{3}$. A simple weight calculation as in Eq. (1) was used to find the weight of the nanoparticle's additions [28].

$C=\frac{m_{1}}{M} \times 100$

$C=$ weight concentrations of nanoparticles,

$m_{1}=$ weight of nanoparticles,

$M=$ total weight of solder alloy $(20 \mathrm{~g})$

This nanocomposite, SB $+3 \%$ Mo solder alloy was let to solidify under room temperature after the remelting process. The solder alloy was then cast into billets of $50 \times 10 \mathrm{~mm}$ as shown in Figure 2(b). The small dimension here will offer as replication of low amount of solder paste used in the electronic industry and at the same time preserve wastage of raw materials. A $16.6 \mathrm{mg}$ sample of unreinforced SB and $14 \mathrm{mg}$ of the $\mathrm{SB}+3 \%$ Mo was placed into an aluminium pan and analyzed using the Differentials Scanning Calorimetry (DSC) to characterize the melting properties. The heat flow was kept at $20.00{ }^{\circ} \mathrm{C} / \mathrm{min}$ with temperature from $100^{\circ} \mathrm{C}$ to $300^{\circ} \mathrm{C}$ under Nitrogen (N) atmosphere.

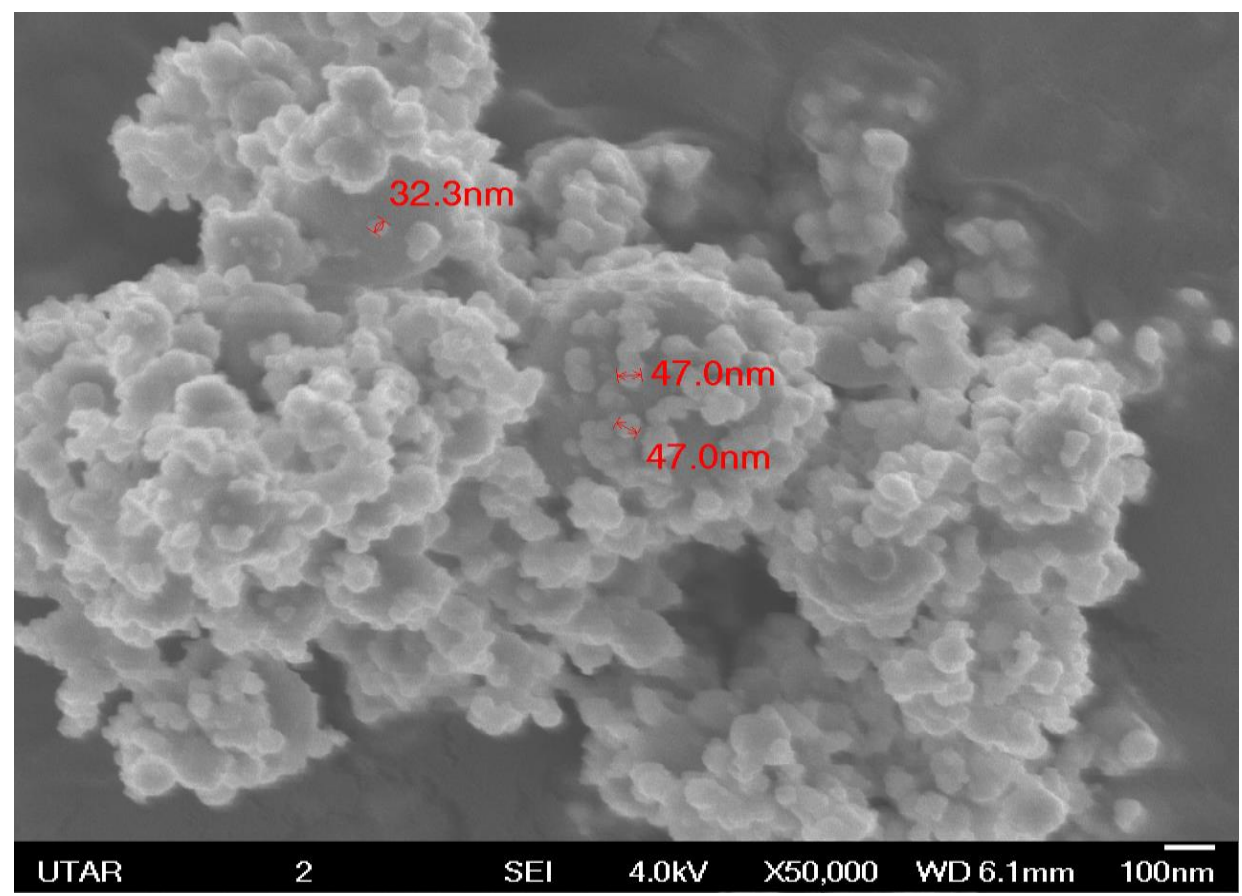

Fig. 1. SEM analysis of Mo nanoparticles size 


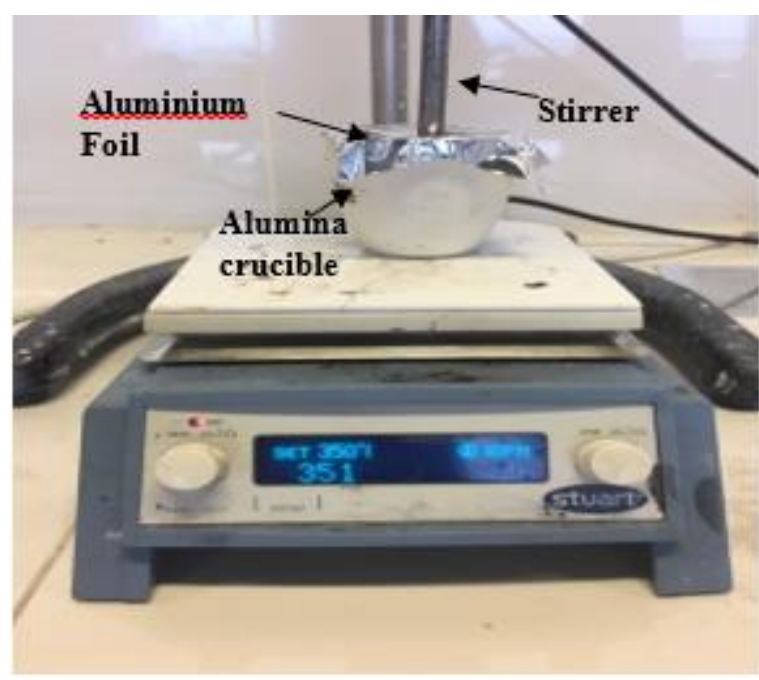

(a) The alumina crucible containing SB added with nanoparticles enclosed with aluminium foil to avoid oxidation

Fig. 2. (a) $S B+3 \%$ Mo under stirring process and (b) $S B+3 \%$ Mo nanoparticles billets

The T-Test was conducted on the SB and the SB + 3\% Mo nanoparticles added solder based on the melting temperature to confirm the statistical difference and the statistics were shown in Table 1. The values of $P=0.000701226(S B+3 \% \mathrm{Mo})$ and $P=0.027492247(\mathrm{SB})$ are less than $(<0.05)$, stating the rejection of null hypothesis and conclude that both samples are statistically different.

Table 1

F-Test for two samples variance using the onset and endset temperatures

\begin{tabular}{lllll}
\hline t-Test: Two-Sample & SB & \multicolumn{3}{c}{ SB + 3\% Mo } \\
\cline { 2 - 5 } Assuming Unequal Variances & Onset & Endset & Onset & Endset \\
& Temperature & Temperature & Temperature & Temperature \\
\hline Mean & 141.782 & 148.138 & 141.79 & 150.844 \\
Variance & 1.61272 & 19.69027 & 0.5101 & 6.93883 \\
Observations & 5 & 5 & 5 & 5 \\
Hypothesized Mean Difference & 0 & & 0 & \\
df & 5 & & 5 & -7.417858519 \\
t Stat & -3.079275942 & & 0.000350613 & \\
$\mathrm{P}(\mathrm{T}<=\mathrm{t})$ one-tail & 0.013746124 & & 2.015048373 & \\
t Critical one-tail & 2.015048373 & & 0.000701226 & \\
$\mathrm{P}(\mathrm{T}<=\mathrm{t})$ two-tail & 0.027492247 & & 2.570581836 & \\
t Critical two-tail & 2.570581836 & & & \\
\hline
\end{tabular}

Microstructural observation of the SB and SB $+3 \%$ Mo was inspected and analysed using a high resolution scanning electron microscope (SEM) equipped with an energy dispersive X-ray spectroscopy analysis (EDX) system. The X-ray diffraction (XRD) was also conducted to examine and analyze the phase formation of the composite solder with the CuKa radiation at an angle of diffraction of $20-80^{\circ}$ with a scan range of $2 \mathrm{~min} /{ }^{\circ}$. The Vickers hardness test was conducted with $1 \mathrm{kgf}$ indentation load with a dwell time of 15 seconds. Five samples each with five indentations were tested to provide accuracy in the result. Eq. (2) was used to calculate the Vickers hardness value and to clarify the statistical difference of these samples, the raw data of the hardness value of $D_{1}$ and $D_{2}$ representing the average diagonal diameters was tested with the analyses of the Fisher StatisticalTest. The two variances (Variance 1: $\mathrm{SB}$ and Variance 2: $\mathrm{SB}+3 \% \mathrm{Mo}$ ) was taken to validate the hypothesis. The calculated $F$ value $(F=0.709652224)$ was larger than the critical $F$ value $\left(F_{\text {critical }}=\right.$ 
$0.314574906)$ stating that the null-hypothesis can be rejected. This statistic is shown in Table 2 . This result validates the statistical difference between the SB and SB + 3\% Mo solder alloy. All the properties were discussed in the upcoming sections.

$H V=1.854\left(\frac{F}{D^{2}}\right)$

$H V=$ Vickers Hardness Number,

$F=$ Indentation Force (1kgf:9.81N),

$D=$ Average diagonal diameter

Table 2

F-Test for two samples variance using diameter of indentations

\begin{tabular}{lll}
\hline & D1 & D2 \\
\hline Mean & 80.122 & 79.505 \\
Variance & 5.869395556 & 8.270805556 \\
Observations & 10 & 10 \\
df & 9 & 9 \\
$F$ & 0.709652224 & \\
$P(F<=f)$ one-tail & 0.308811638 & \\
F Critical one-tail & 0.314574906 & \\
\hline
\end{tabular}

\section{Results and Discussions}

\subsection{Melting Temperature}

Melting temperatures are crucial asset to a solder alloy because the temperature applied on the electronic board influences the energy consumptions and the thermal warpage that may deteriorate the solder interconnections [87]. The unreinforced SB and the SB 3\% + Mo solder alloy's thermal properties was investigated using the DSC heating (endothermic) and cooling (exothermic) curves that is represented in Figure 3. The solidus $T_{S}$, melting $T_{M}$, liquidus $T_{L}$ and pasty range $T_{R}$, ( $T S_{\text {heating }}-$ $\mathrm{Ts}_{\text {cooling }}$ ) temperatures of the SB and SB $+3 \%$ Mo nanoparticles solder for the melting curve are shown in Table 3. The pasty range contributes to the prediction of the microstructure formation because at this range, the solidification occurs to form grains of the solder and range effects change of the heat capacity between solid and liquid and change in the heat fusion [14]. Both DSC readings for the heating curve show a sharp peak with the melting temperature $\mathrm{T}_{\mathrm{M}}$ of $142.25^{\circ} \mathrm{C}$ for the $\mathrm{SB}$ solder alloy and $148.67^{\circ} \mathrm{C}$ for the $3 \%$ Mo nanoparticles added SB solder alloy. The specific heat capacity of the $\mathrm{SnBi}$ and $\mathrm{SB}+3 \% \mathrm{Mo}$ solder is $47.53 \mathrm{~J} / \mathrm{g}$ and $7.78 \mathrm{~J} / \mathrm{g}$ respectively, and demonstrates that the additions of the Mo nanoparticles reduces the specific heat capacity of the pristine solder. The Mo nanoparticles influenced an elevation of $\sim 6^{\circ} \mathrm{C}$ in the melting point compared to the unreinforced SB solder. Increase of melting temperature with nanoparticles additions are collectively agreed in other

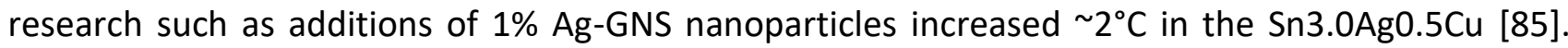
Additions of $0.1 \% \mathrm{Al}_{2} \mathrm{O}_{3}$ nanoparticles increased $\sim 4^{\circ} \mathrm{C}$ in the $\mathrm{Sn} 3.5 \mathrm{Ag} 0.7 \mathrm{Cu}$ [47]. Additions of $0.2 \% \mathrm{TiC}$ nanoparticles increased $\sim 5^{\circ} \mathrm{C}$ in the $\mathrm{Sn3} .0 \mathrm{Ag} 0.5 \mathrm{Cu}$ [18]. Additions of $1 \% \mathrm{Al}_{2} \mathrm{O}_{3}$ nanoparticles increased $\sim 2^{\circ} \mathrm{C}$ in the Sn3.5Ag0.7Cu [55]. And additions of $1.5 \% \mathrm{Ag}$ nanoparticles increased $\sim 1^{\circ} \mathrm{C}$ in the Sn9Zn [9]. The reason behind the slight increase in the melting point is because of the occurrence of melt undercooling before solidification endured by the Mo nanoparticles reinforced SB solder alloy. The degree of undercooling indicates the level of difficulty of a nucleation process during solidification. The degree of undercooling for the reinforced SB solder alloys was $2.45^{\circ} \mathrm{C}\left(12.7^{\circ} \mathrm{C}\right.$ vs $\left.10.3^{\circ} \mathrm{C}\right)$ lower compared to the bare SB solder alloy as shown in Table 3. A smaller degree of undercooling is 
necessary for better solder solidification. Another possible explanation on the increase in the melting temperature is the increase in surface instability of the molten SB solder as a reason of higher surface energy encountered upon presence of Mo nanoparticles. Unlike the unreinforced SB solder, the energy required to break free the atoms are higher in the Mo nanoparticles reinforced SB solder alloy. Ding et al., [20] reported similar information after the additions of $\mathrm{Al}_{2} \mathrm{O}_{3}$ nanoparticles in the Sn9Zn solder system. According to Zhu et al., [95], the increase in the melting point is also due to the high melting point of the nanoparticle's material (e.g. Mo nanoparticles melting point $=2623^{\circ} \mathrm{C}$ ). Noor and Singh [23] also mentioned this explanation in a review study. As the remelting temperature was kept at $350^{\circ} \mathrm{C}$ in this research during mixing, there would be no chance for the supplied heat to melt the Mo nanoparticles, which possesses a melting point of $2623^{\circ} \mathrm{C}$.

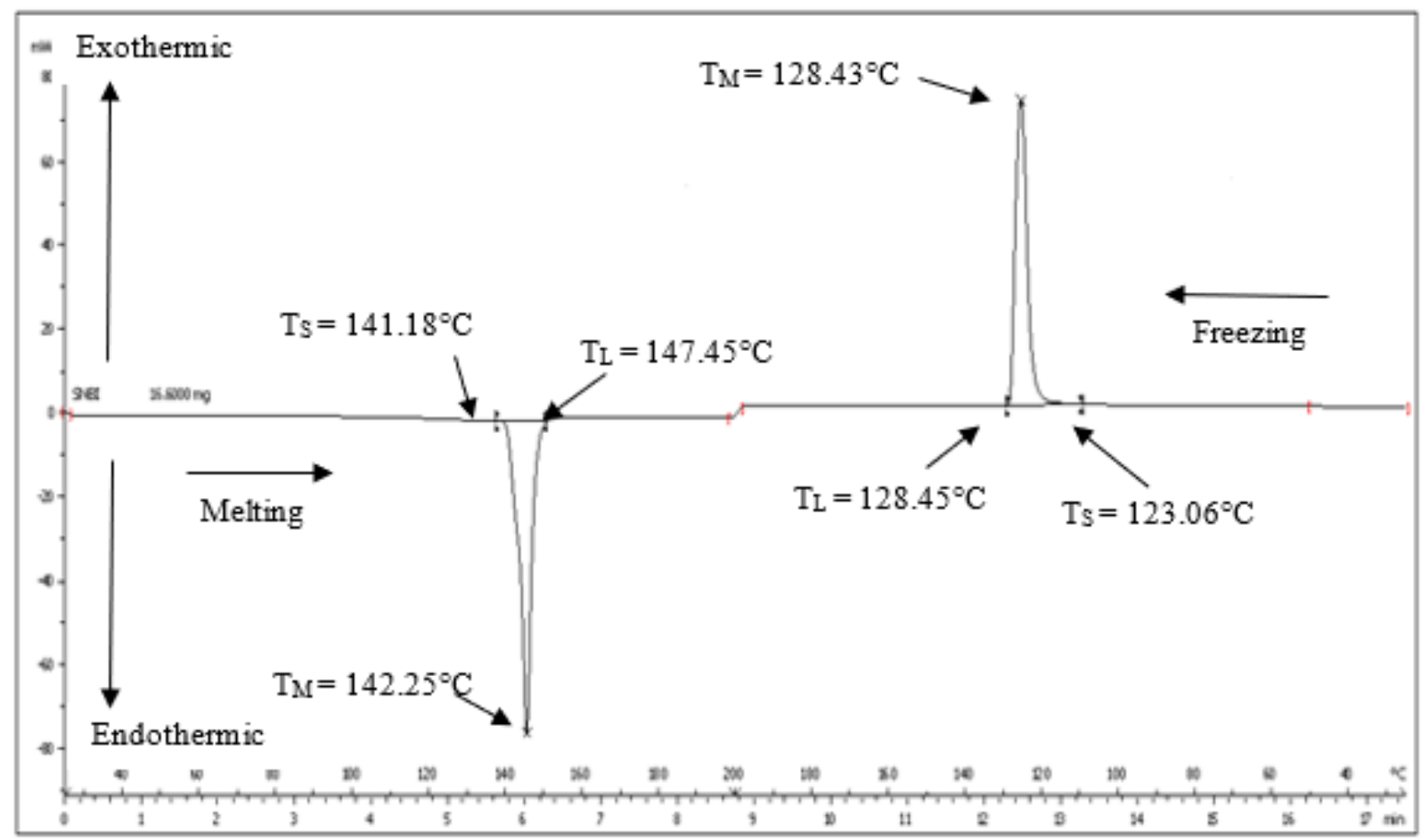

(a) SB 


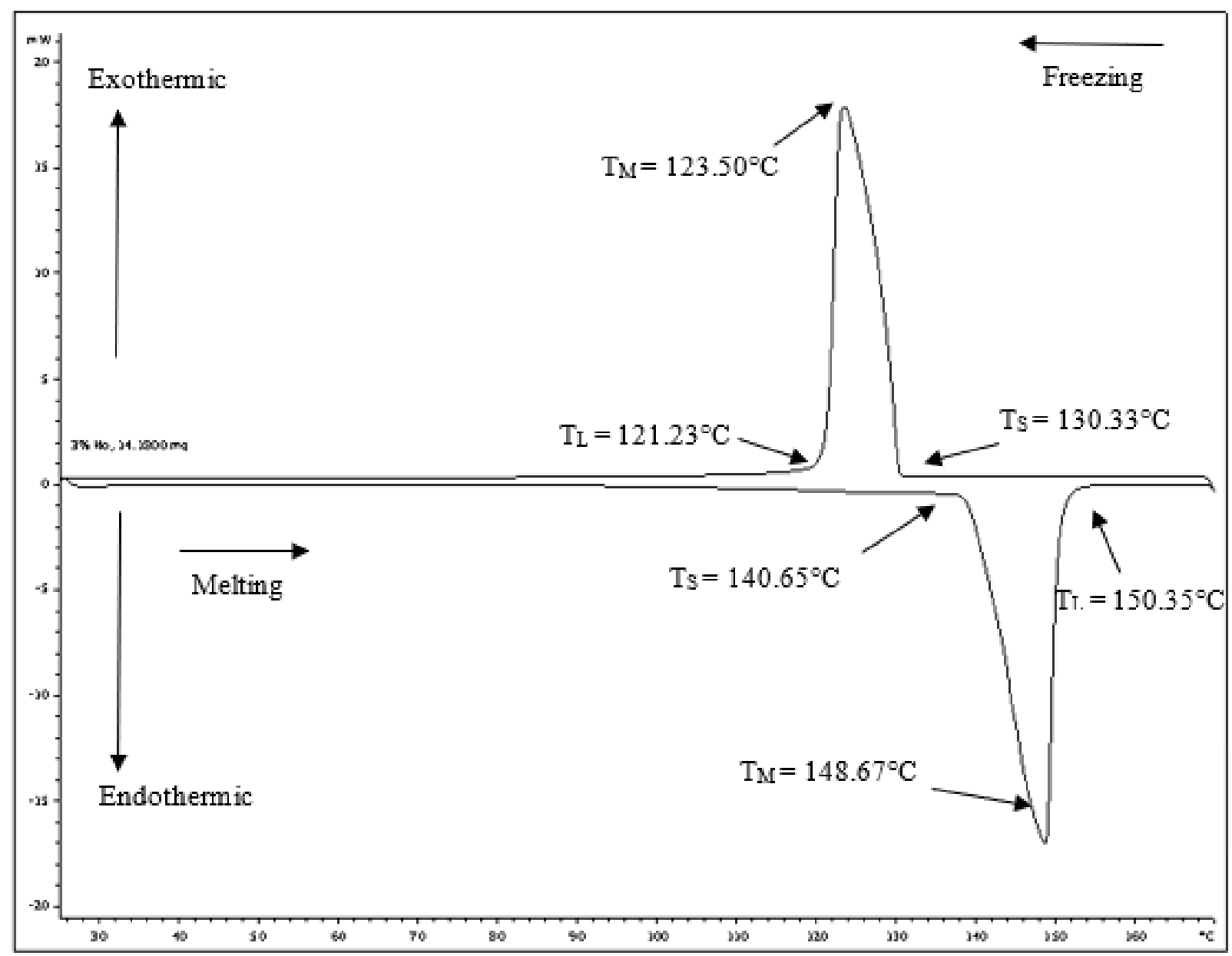

(b) $\mathrm{SB}+3 \% \mathrm{Mo}$

Fig. 3. DSC curve of (a) SB solder alloy and (b) SB + 3\% Mo nanoparticles

Table 3

Thermal properties of SB and SB + 3\% Mo nanoparticles

\begin{tabular}{|c|c|c|c|c|c|}
\hline Solder & $\begin{array}{l}\text { Solidus } \\
\text { Temperature, } \\
\text { TS }\left({ }^{\circ} \mathrm{C}\right)\end{array}$ & $\begin{array}{l}\text { Melting } \\
\text { Temperature, } \\
\mathrm{TM}\left({ }^{\circ} \mathrm{C}\right)\end{array}$ & $\begin{array}{l}\text { Liquidus } \\
\text { Temperature, } \mathrm{TL} \\
\left({ }^{\circ} \mathrm{C}\right)\end{array}$ & $\begin{array}{l}\text { Pasty Range, } \\
\operatorname{TR}\left({ }^{\circ} \mathrm{C}\right)\end{array}$ & $\begin{array}{l}\text { Undercooling } \\
\text { (Tsheating - } \\
\text { Ts cooling) }\left({ }^{\circ} \mathrm{C}\right)\end{array}$ \\
\hline SB & 141.18 & 142.25 & 147.45 & 1.07 & 12.75 \\
\hline $\begin{array}{l}\mathrm{SB}+3 \% \mathrm{Mo} \\
\text { nanoparticles }\end{array}$ & 140.62 & 148.67 & 150.35 & 8.05 & 10.30 \\
\hline
\end{tabular}

The solidus temperature of the Mo added SB solder reduces compared to the bare SB solder and contributed due to the melt undercooling affect as well. The change in the solidus temperature increases the pasty range of the 3\% Mo nanoparticles added SB solder. However, the increase in the pasty range was not evidently large and did not affect the microstructure formation, which will be discussed in the next section. The range is still considered as the range closer to the eutectic range. Matching to the Lindemann's melting theory as well, a materials melting point is dependent on the energy required to overcome the interatomic interaction or in other words, it is an intrinsic property of the molecular in the SB solder alloy which is not affected by the presence of Mo nanoparticles [48]. 


\subsection{Microstructure of SB and SB + 3\% Mo Nanoparticles Solder Alloy}

The SEM images in Figure 4 shows the microstructure of the bare SB solder alloy with $1 \mathrm{~K}$ magnification to demonstrate the (a) lamellar structure (b) $\beta$-Sn area and (c) Bi phases on the solder. The Figure 5(a), Figure 5(b) and Figure 5(c) depicts the microstructures of the SB+3\% Mo nanoparticles solder alloys at different places with the presence of Mo nanoparticles visible clearly. In both Figure 4 and Figure 5, there is a clear existence of lamellar solder alloy consists of the lamellar structure identified as $\beta$-Sn (dark phase) and Bi (light phases) confirmed by the EDX analysis with the points shown in Figure 4(b) and Figure 4(c). Shen et al., [71] provided a similar observation of the lamellar structured formation in the $\mathrm{SnBi}$ solder matrix. The Bi element is known to not react with the $\mathrm{Sn}$ to form any IMC in the solder matrix because of its low solubility. In fact, the phases present matches with the $\mathrm{SnBi}$ phase diagram at a temperature of $140^{\circ} \mathrm{C}$ (melting temperature). The Mo nanoparticles have no solubility in the $\mathrm{Sn}$ matrix and $\mathrm{Bi}$ and do not react with these elements, which is evident from the SEM image of Figure 5. The Mo nanoparticles agglomerates and appear on top of the lamellar Sn and Bi phases as shown in Figure 5. The EDX analysis in Figure 5(a) and Figure 5(b) confirms the presence of Mo nanoparticles by taking the nominal weight percentage. Further confirmation of the Mo nanoparticles in the SB solder alloy is proven with the XRD test results in Figure 6(a). The peaks of Mo in the $\mathrm{SB}+3 \% \mathrm{Mo}$ in Figure 6(a) matches the strongest peak of $2 \theta=$ $40.5494^{\circ}, 58.668^{\circ}$ and $73.7225^{\circ}$ in Figure 6(b). Comparing XRD results of the pure SB, the Mo peaks earlier did not appear as shown in Figure 6(c). The Mo nanoparticles can change the growth velocity of the SB solder alloy as it appears as discrete particles. Haseeb et al., [38] also established similar incidence with the reinforcement of Mo nanoparticles in $\mathrm{Sn}-3.8 \mathrm{Ag}-0.7 \mathrm{Cu}$ solder alloy. As observed in Figure 5 (c), the yellow borders enclosing the lamellar structure of the SB $+3 \%$ Mo solder alloy were finer. The Bi phases were more elongated and narrower (closely packed) compared to the Bi phase in the pure SB solder alloy. The EDX analysis in Figure 5(c) confirms that this area was accommodated by the $\mathrm{Sn}$ and $\mathrm{Bi}$ while the Mo particles are not much existent. This observation explains that Mo nanoparticles affect the solidification and grain growth of the $\beta-S n$ and $\mathrm{Bi}$. The Mo nanoparticles act as a separate site for nucleation during solidification that restricts the surface energy of the molten solder alloy. Hence, the high activation energy of the $\mathrm{Sn}$ would be limited, resulting in a smaller $\beta-\mathrm{Sn}$ matrix. This theory was agreed by Xing et al., [84]. This statement was also linked to the research by Shin et al., [72] explaining a similar reason with SiC nanoparticles additions in Sn58Bi solder alloy. Another study by Yang et al., [90] with additions of $0.25 \%$ Mo in the Sn58Bi shared similar findings. Meanwhile, the agglomerations of Mo nanoparticles observed in Figure 5 did not to affect the refinement of the microstructure (does not act as a nucleation site) since the weight percentage is low. This proclamation was observed in the investigations of Zhang and Tu [94]. Moreover, during the molten state, the highly viscous molten SB rejects the agglomerated Mo nanoparticles. A

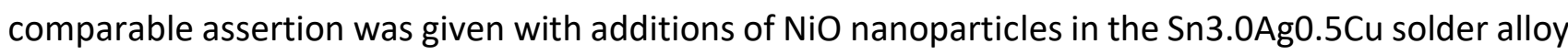
[15]. However, it is important to control the limit of the weight percentage additions of the nanoparticles since higher content will deteriorate the grain refining process which results in increased $\beta$-Sn grain sizes as reported by Jung et al., [46]. 

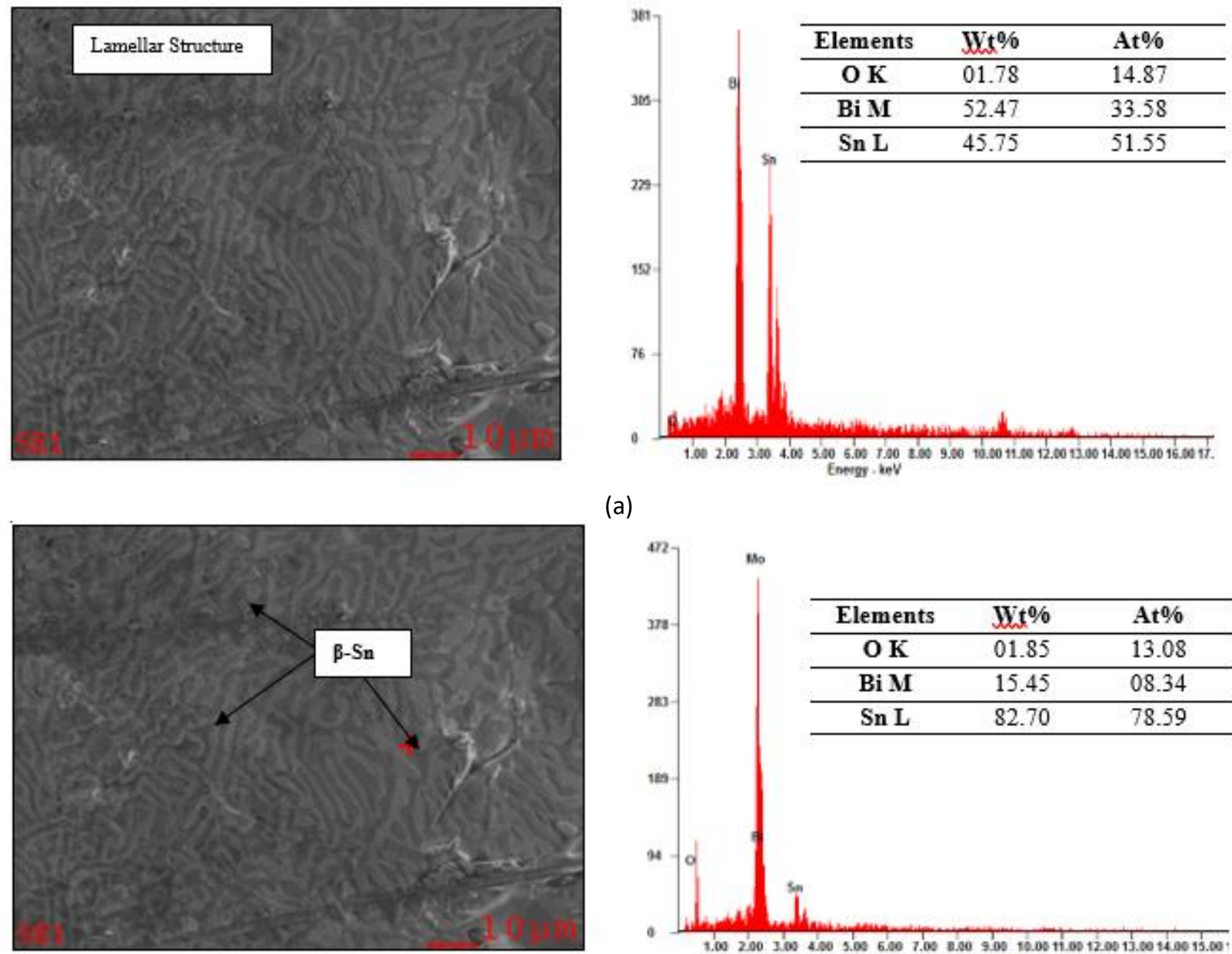

(a)

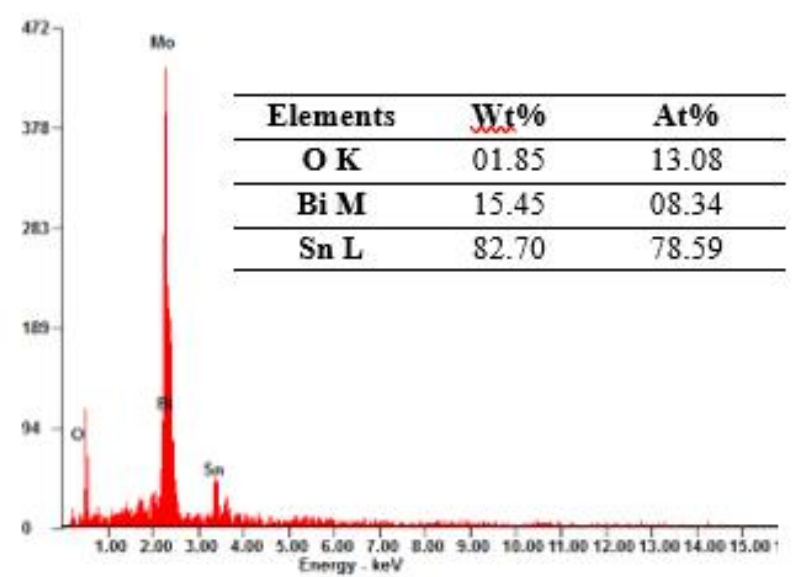

(b)
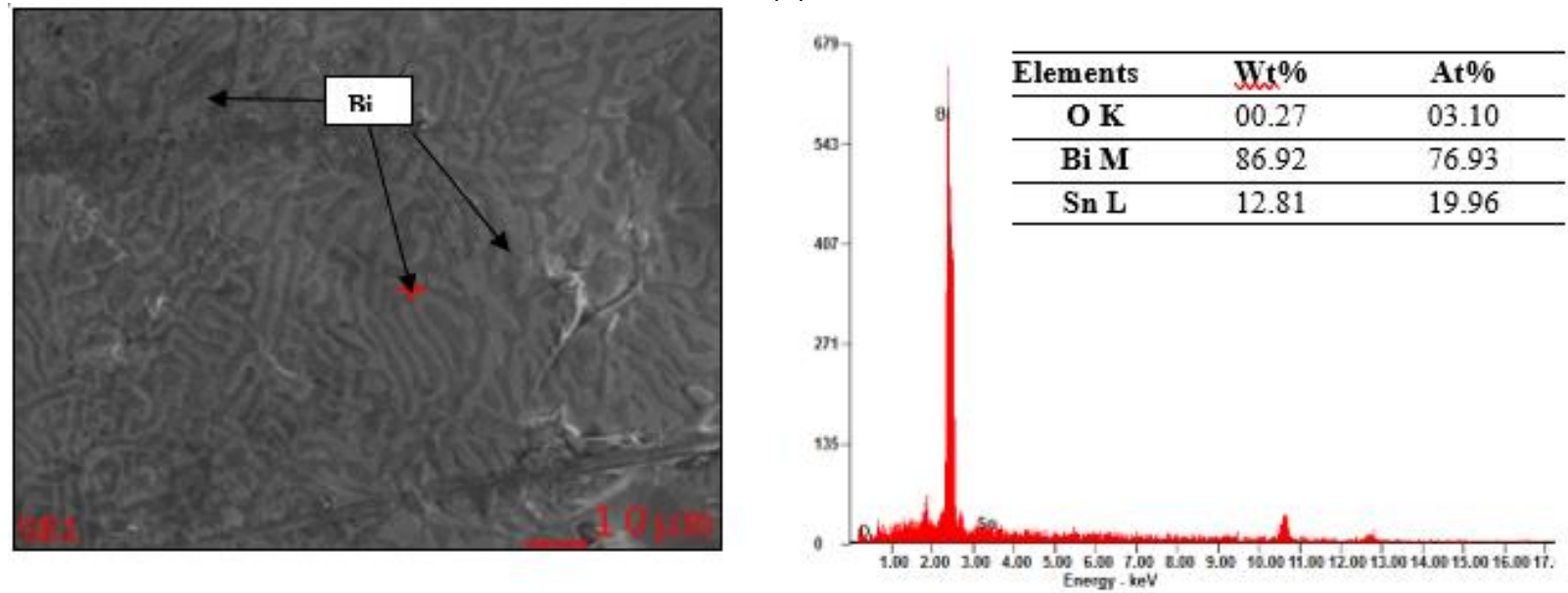

(c)

Fig. 4. (a), (b) and (c). Microstructure of pure SB 

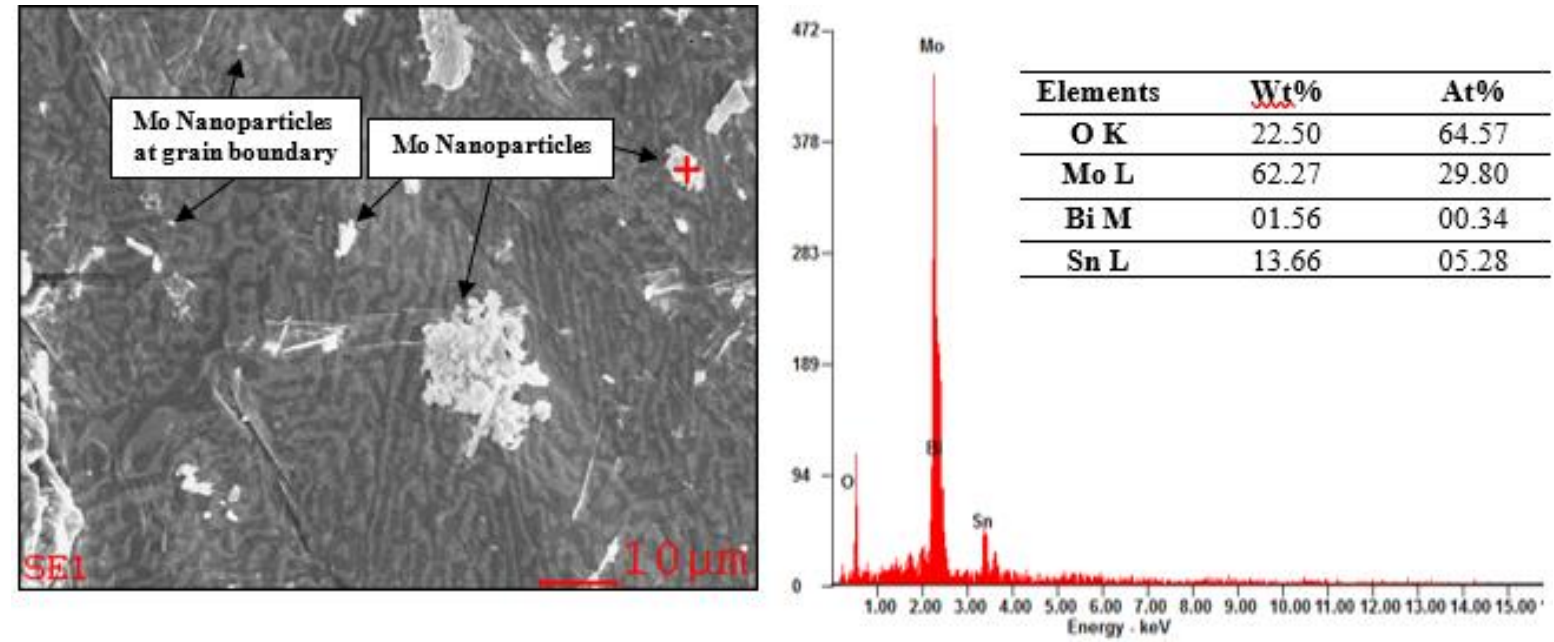

(a)
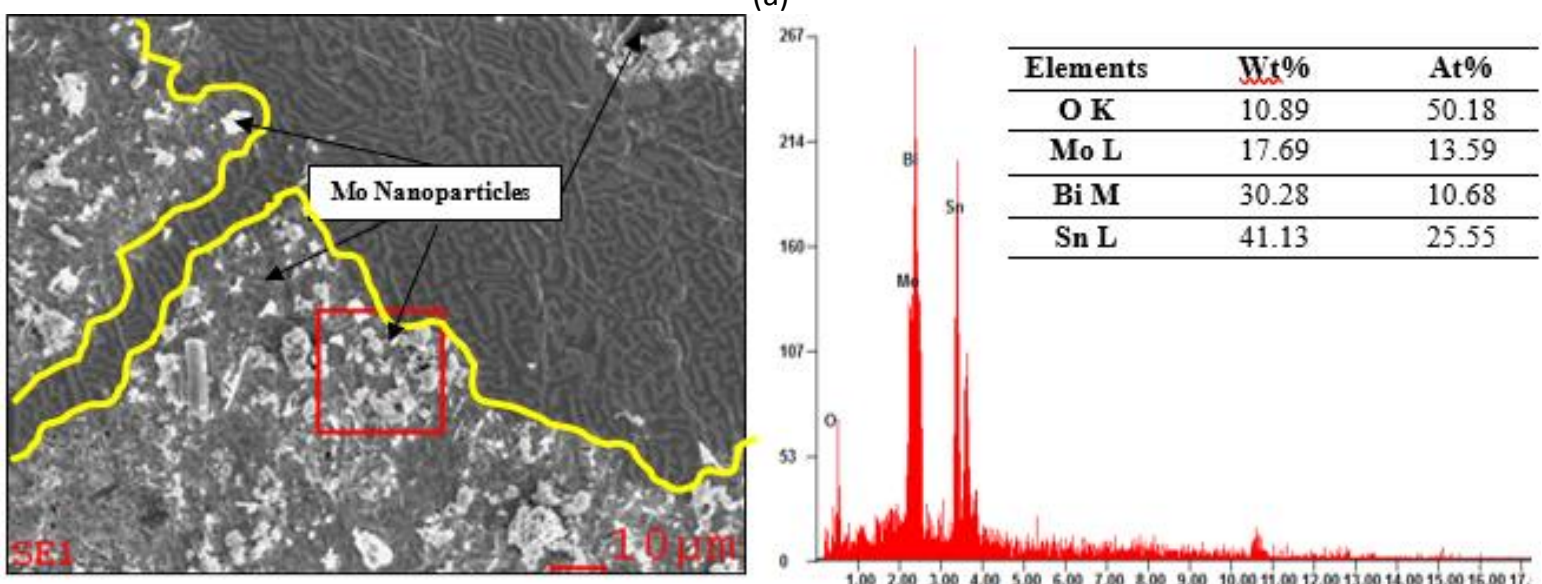

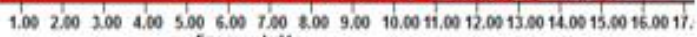

(b)
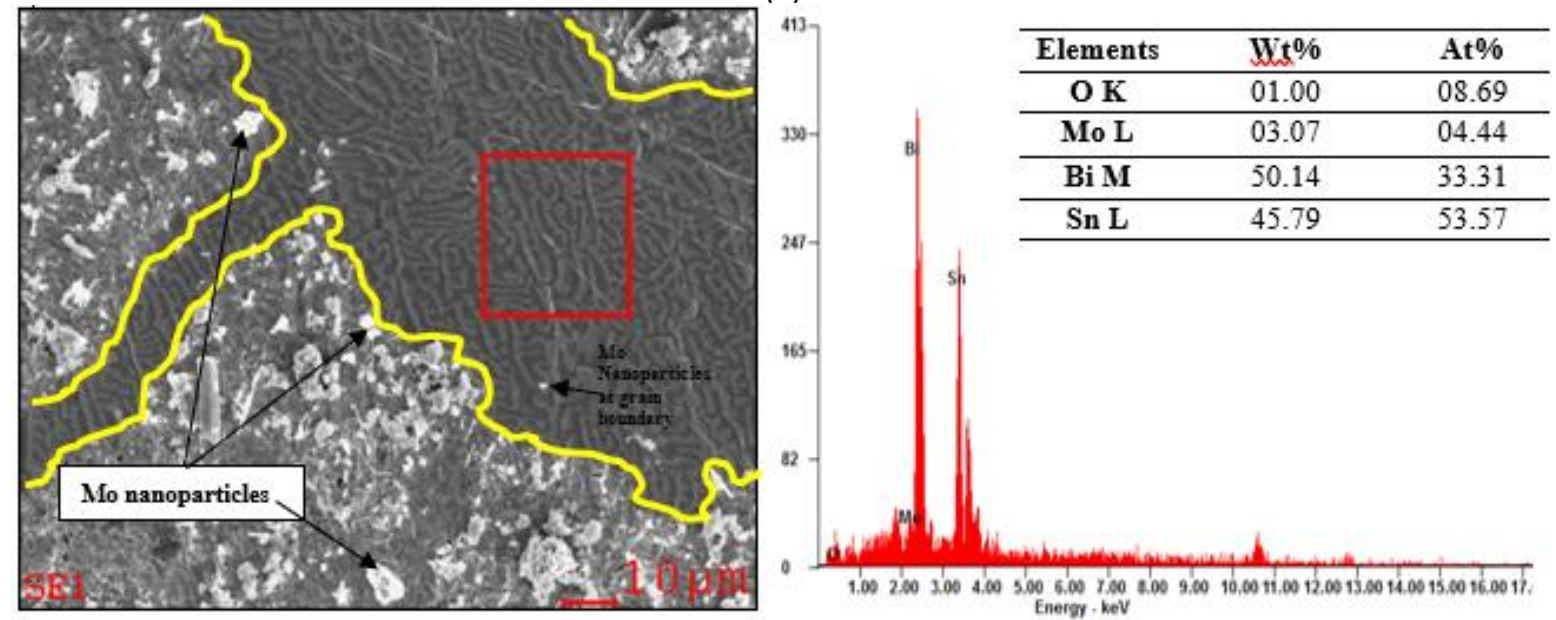

(c)

Fig. 5. (a), (b) and (c). Microstructure of SB $+3 \%$ Mo nanoparticles 


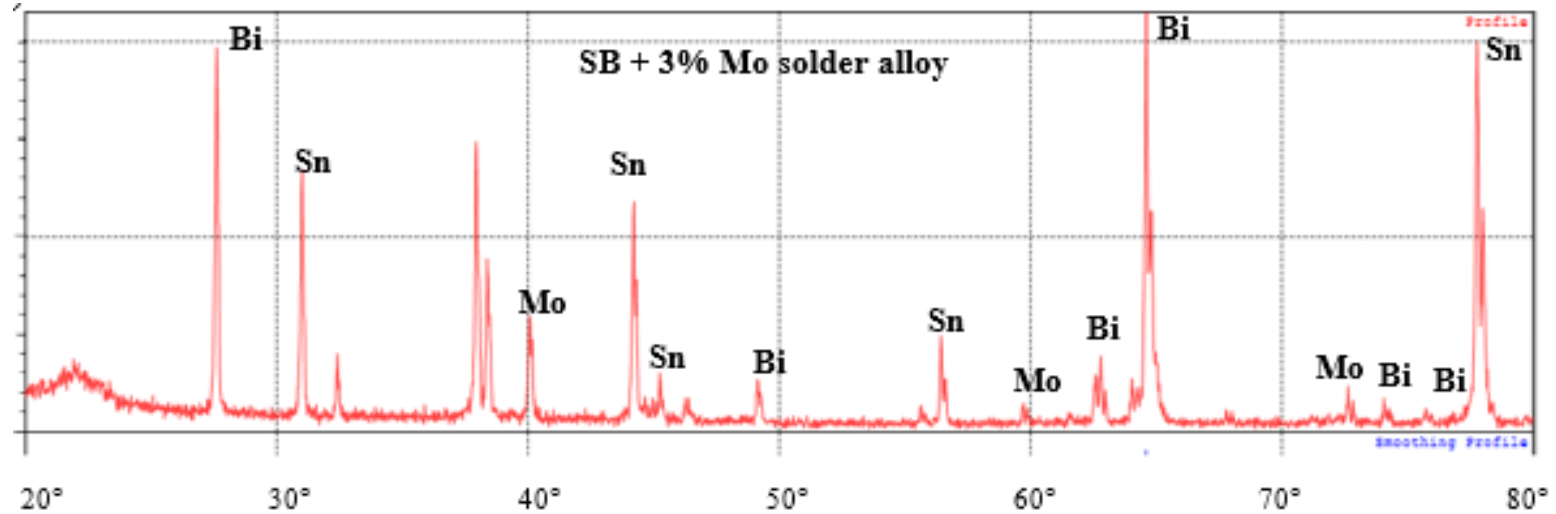

(a)

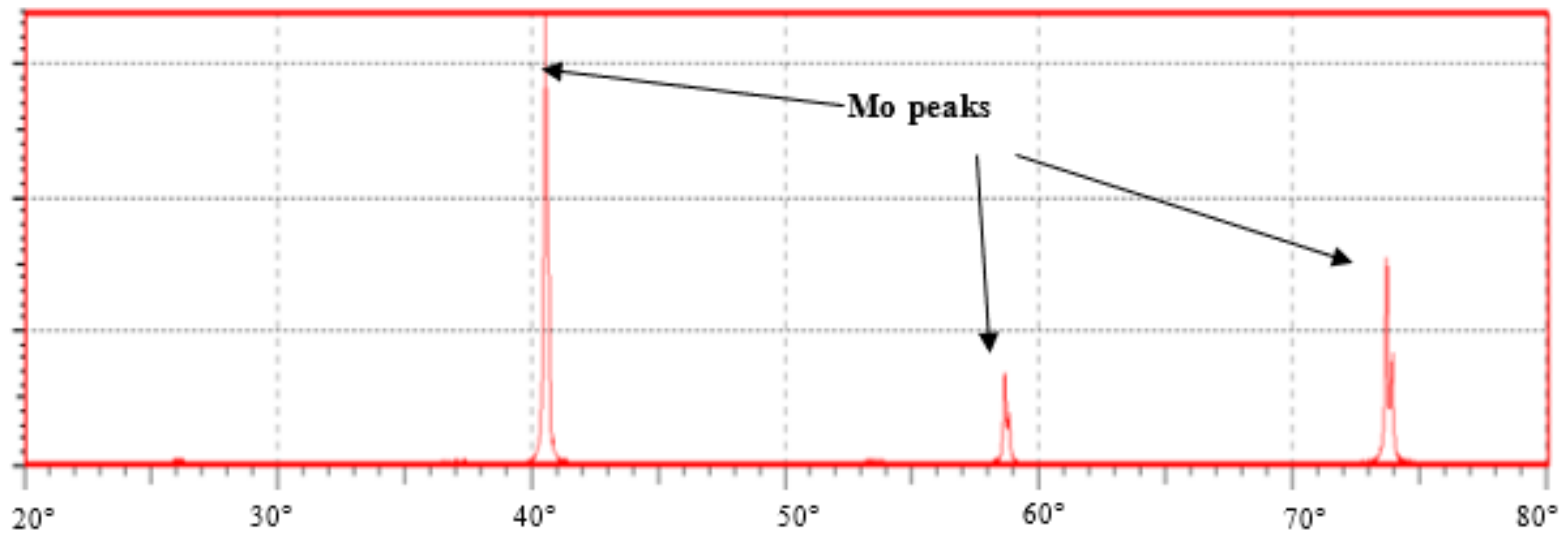

(b)

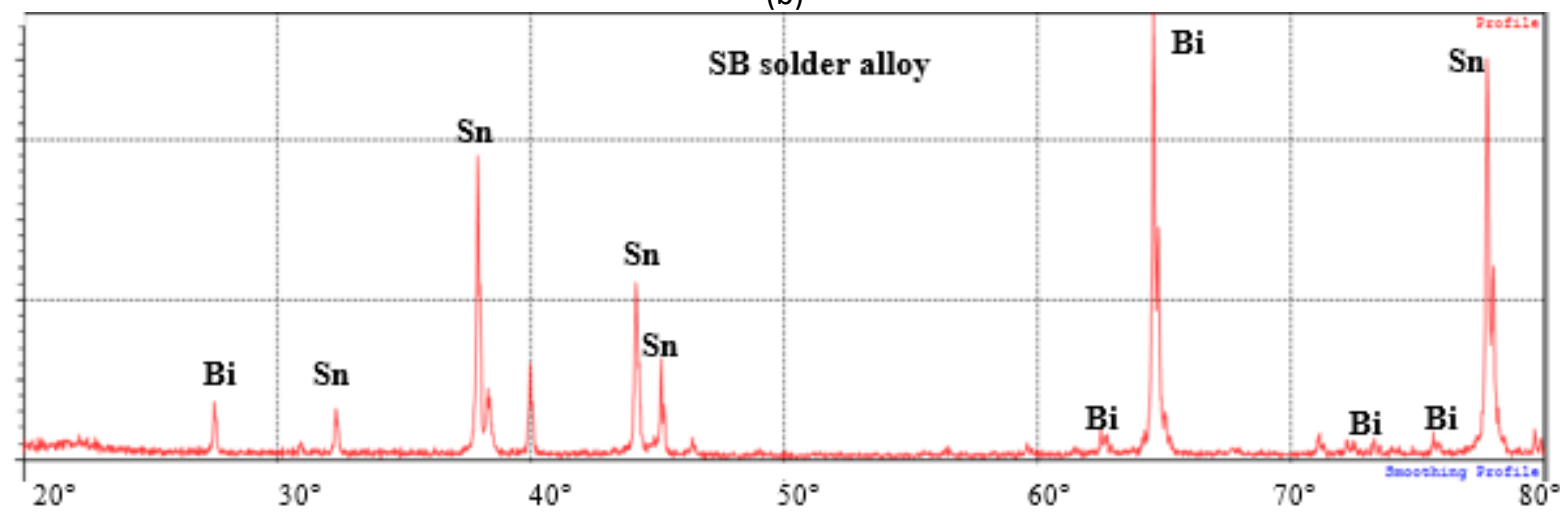

(c)

Fig. 6. XRD result of (a) SB $+3 \% \mathrm{Mo}$, (b) Mo and (c) Pure SB solder alloy

\subsection{Vickers Microhardness SB and SB + 3\% Mo Nanoparticles Solder Alloy}

Table 4 gathered the Vickers microhardness results of both the bare SB and the $3 \%$ Mo nanoparticles reinforced solder alloy from this research. The results show an increase of $2 \%$ for the hardness value for the 3\% Mo reinforced SB solder alloy. The hardness value increment is clearly due to the presence of the Mo nanoparticles which harder than the $\mathrm{Sn}$ and $\mathrm{Bi}$. 


\section{Table 4}

Vickers hardness of SB+3\% Mo and SB solder alloy

\begin{tabular}{lllllll} 
Solder & \multicolumn{2}{l}{ Vickers Hardness (Hv) } & & & \\
& Indentation 1 & Indentation 2 & Indentation 3 & Indentation 4 & Indentation 5 & Average \\
\hline SB + 3\% Mo & $29.73 \pm 6$ & $28.02 \pm 6$ & $29.82 \pm 6$ & $29.73 \pm 6$ & $28.58 \pm 6$ & $29.2 \pm 6$ \\
SB & $27.84 \pm 6$ & $27.59 \pm 6$ & $29.39 \pm 6$ & $29.26 \pm 6$ & $29.82 \pm 6$ & $28.7 \pm 6$ \\
\hline
\end{tabular}

The physical property of these Mo nanoparticles which do not take part in any diffusion process enables the Mo particles to act as discrete particles. These Mo particles impede the dislocation motion and in mechanical terms, this phenomenon is known as the second phase hardening mechanism [10]. A second phase hardening mechanism occurs when small particles (resembled by the Mo nanoparticles) impede the dislocation motion upon stress induction [33]. Obeying to the theory of dispersion, these Mo nanoparticles pins along the grain boundary in the SB solder alloy. As more pinning of Mo nanoparticles at the grain boundary, the dislocation path needs to bend over or penetrate through these high dense dislocations, contributing to increasing in the stress/load [21]. Since the Mo particles could not be penetrated, dislocations path will need to loop over the Mo particles and with more piled dislocation loops being formed, an increase in the dislocation density occurs. This high dislocation density consequently increases the resistance of deformation of the solder. Figure 7 shows the schematic diagram of the explanation above. The Zener pinning theory could be also used to find the analytical result of the pinning stress but this was theory is not discussed in this research, but can be found elsewhere. On the other hand, the Mo nanoparticles can increase the stress/load needed to penetrate the solder alloy and as for that, the load is transferred to the Mo nanoparticles. This information stated alike by Kumar et al., [51] with incorporation of the single-wall carbon nanotube (SWCNT) in the Sn-3.8Ag-0.7Cu solder alloy. This phenomenon is defined as the load-bearing effect [29]. The microstructure morphology of the SB $+3 \%$ Mo nanoparticles likewise contributes to the increase in the hardness. The uniform microstructure with finer $\beta$-Sn with the narrower lamellar structures is another factor that increases the hardness. Theoretically, a higher surface area of the nanoparticles per unit volume of the total solder alloy can increase the hardness of a material [48]. Yahaya et al., [88] reported this clarification with TiO2 nanoparticles additions in

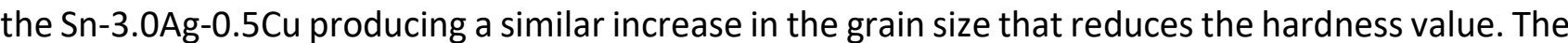
Mo nanoparticles here provides another form of strengthening mechanism as solid particulates and increases the hardness of the solder. A study by Tsukamoto et al., [37] in inspecting the influence of $\mathrm{Ni}$ particles in Sn-0.7Cu solder alloy correlates with this justification. Contrariwise, the stress/load easily penetrated deeper in the bare SB solder alloy because of less dislocation and absence of discrete Mo nanoparticles to act as second phase strengthening mechanism.

\section{Discussion on Mechanisms Influencing the Behaviour of Mo Nanoparticles in The SB Solder Alloy}

In this research, the Mo nanoparticles were mechanically mixed into the SB solder alloy where the Mo nanoparticle's melting temperature is $T M=2623^{\circ} \mathrm{C}$. There would not be any dissolution of these nanoparticles because of the lower temperature of $600^{\circ} \mathrm{C}$ used to melt the $\mathrm{Sn}$ and $\mathrm{Bi}$ together with the Mo nanoparticles. Therefore, as mentioned, the Mo nanoparticles will only exist as discrete particles. As spell out by Haseeb and Leng [39], nanoparticles additions should be ranging between $5-10 \mathrm{~nm}$ in diameters to fully react with the molten solder alloy. In this research, the size of the nanoparticles was an average of $42 \mathrm{~nm}$ and at this size, it is not possible for any reaction to take place. Furthermore, Wattanakornphaiboon et al., [82] states that nanoparticles will not involve in any diffusion with the Sn due to nature of its low solubility. Consequently, the Mo nanoparticles will opt to accumulate along the grain boundaries (high-energy area) and the surface of the molten SB solder 
alloy. This is because of the nature of the nanoparticles of being a surface-active element. It represents the distribution of nanoparticles in a molten solder alloy as per dispersed nanoparticles and as agglomerated nanoparticles [21]. It therefore confirms the presence of these Mo nanoparticles in this research affect the formation of grains ( $\beta$-Sn and $\mathrm{Bi}$ ) in the microstructure by changing the driving force and the growth velocity that resulted in the nearer lamellar gaps between the microstructure as noticed in Figure 5. In addition, during solidification, these Mo nanoparticles in the $\mathrm{Sn}$ matrix promotes heterogeneous nucleation site that makes the spacing between the lamellar structures smaller. Research by Billah et al., [13] reported likewise with Ni particles additions.

This study also states that the hardness of the SB $+3 \%$ Mo nanoparticles and the strengthening effect can only be achieved with proper mixing of the Mo nanoparticles in the SB solder alloy. Therefore, any presence of high content of Mo nanoparticles are found to be less ductile and can degrade the strength of the SB solder alloy. The nanosized Mo particles act as load-bearing effect that resists the load by contributing as another strengthening insertion to the solder. This also could be related to the Orowan strengthening stating that the presence of the nanoparticles itself contributes as hardening mechanism that endures the loads upon induced stress. Moreover, Mo nanoparticles deeds as second phase particles in the solder matrix and will enhance the hardness of the solder alloy by not allowing slip plane to pass through it.

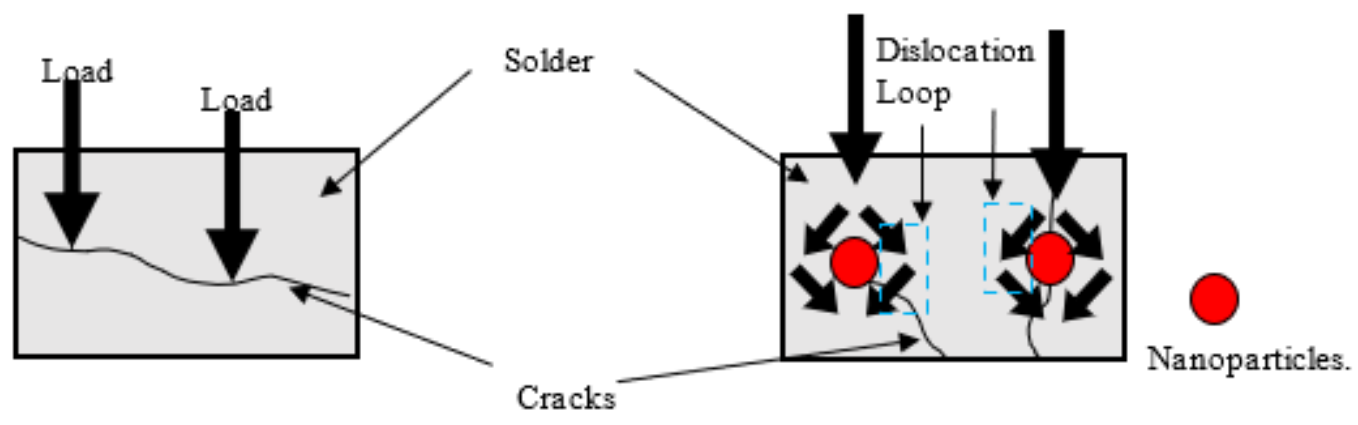

Fig. 7. Schematic diagram of stress/load penetration (a) bare solder and (b) nanoparticles added solder

\section{Conclusions}

This research examined the effects of 3\% Mo nanoparticles addition on the thermal, microstructure and hardness properties of Sn58Bi solder alloy. Proper mixing of the Mo nanoparticles in the SB solder alloy appears to improve the microstructural and hardness properties in this study. The following conclusions are drawn from the results and discussion

i. The 3\% Mo nanoparticles were successfully mixed with the SB solder alloy supported with the EDX and XRD analysis. The presence of Mo nanoparticles was visible through the SEM images.

ii. The addition of $3 \%$ Mo nanoparticles in the SB solder alloy increased the melting temperature in a minimal range $\left(\sim 6^{\circ} \mathrm{C}\right)$ and is due to the melt undercooling before solidification. The melting properties are not to be affected by the nanoparticles addition according to the Lindemann theory.

iii. The microstructure of 3\% Mo added SB solder alloy had significant changes as the lamellar structure was observed to have closer gaps. This is explained by the surface adsorption theory where the Mo nanoparticles act as a site for nucleation and also reduces the growth velocity of $\beta$-Sn.

iv. Vickers microhardness of the $3 \%$ Mo added solder was enhanced by a degree of $2 \%$ compared to the bare SB solder alloy. The Mo nanoparticle's influence in the microstructure produces a 
more uniform microstructure (nearer lamellar structure) and contributes to this hardness enhancement. The Mo nanoparticles itself behaves as second phase insertion in the matrix that influences the higher hardness value.

\section{References}

[1] Fawzy, A., S. A. Fayek, M. Sobhy, E. Nassr, M. M. Mousa, and G. Saad. "Effect of ZnO nanoparticles addition on thermal, microstructure and tensile properties of Sn-3.5 Ag-0.5 Cu (SAC355) solder alloy." Journal of Materials Science: Materials in Electronics 24, no. 9 (2013): 3210-3218. https://doi.org/10.1007/s10854-013-1230-2

[2] El-Daly, A. A., A. E. Hammad, G. S. Al-Ganainy, and A. A. Ibrahiem. "Design of lead-free candidate alloys for lowtemperature soldering applications based on the hypoeutectic Sn-6.5 Zn alloy." Materials \& Design (1980-2015) 56 (2014): 594-603. https://doi.org/10.1016/i.matdes.2013.11.064

[3] El-Daly, A. A., A. Fawzy, S. F. Mansour, and M. J. Younis. "Novel SiC nanoparticles-containing Sn-1.0 Ag-0.5 Cu solder with good drop impact performance." Materials Science and Engineering: A 578 (2013): 62-71. https://doi.org/10.1016/i.msea.2013.04.022

[4] Hammad, A. E. "Investigation of microstructure and mechanical properties of novel Sn-0.5 Ag-0.7 Cu solders containing small amount of Ni." Materials \& Design $50 \quad$ (2013): $108-116$. https://doi.org/10.1016/i.matdes.2013.03.010

[5] Hammad, A. E., and A. A. Ibrahiem. "Enhancing the microstructure and tensile creep resistance of Sn-3.0 Ag-0.5 Cu solder alloy by reinforcing nano-sized ZnO particles." Microelectronics Reliability 75 (2017): 187-194. https://doi.org/10.1016/i.microrel.2017.07.034

[6] Haseeb, A. S. M. A., M. M. Arafat, S. L. Tay, and Y. M. Leong. "Effects of metallic nanoparticles on interfacial intermetallic compounds in tin-based solders for microelectronic packaging." Journal of Electronic Materials 46, no. 10 (2017): 5503-5518. https://doi.org/10.1007/s11664-017-5591-9

[7] Abdelhadi, Ousama. "Size effects in tin-based lead-free solder joints: Kinetics of bond formation and mechanical characteristics." PhD diss., University of Alabama Libraries, 2013.

[8] Abtew, Mulugeta, and Guna Selvaduray. "Lead-free solders in microelectronics." Materials Science and Engineering: R: Reports 27, no. 5-6 (2000): 95-141. https://doi.org/10.1016/S0927-796X(00)00010-3

[9] Ahmed, Mansur, Tama Fouzder, Ahmed Sharif, Asit Kumar Gain, and Yan Cheong Chan. "Influence of Ag microparticle additions on the microstructure, hardness and tensile properties of Sn-9Zn binary eutectic solder alloy." Microelectronics Reliability 50, no. 8 (2010): 1134-1141. https://doi.org/10.1016/j.microrel.2010.03.017

[10] Amagai, Masazumi. "A study of nanoparticles in Sn-Ag based lead free solders." Microelectronics Reliability 48, no. 1 (2008): 1-16. https://doi.org/10.1016/j.microrel.2007.05.004

[11] Ani, Fakhrozi Che, Azman Jalar, Abdullah Aziz Saad, Chu Yee Khor, Roslina Ismail, Zuraihana Bachok, Mohamad Aizat Abas, and Norinsan Kamil Othman. "SAC-xTiO2 nano-reinforced lead-free solder joint characterizations in ultra-fine package assembly." Soldering \& Surface Mount Technology 30, no. 1 (2018): 1-13. https://doi.org/10.1108/SSMT04-2017-0011

[12] Bang, Junghwan, Dong-Yurl Yu, Yong-Ho Ko, Min-Su Kim, Hiroshi Nishikawa, and Chang-Woo Lee. "Intermetallic compound formation and mechanical property of $\mathrm{Sn}-\mathrm{Cu}-\mathrm{xCr} / \mathrm{Cu}$ lead-free solder joint." Journal of Alloys and Compounds 728 (2017): 992-1001. https://doi.org/10.1016/i.jallcom.2017.09.011

[13] Billah, Md Muktadir, Kazi Mohammad Shorowordi, and Ahmed Sharif. "Effect of micron size Ni particle addition in Sn-8Zn-3Bi lead-free solder alloy on the microstructure, thermal and mechanical properties." Journal of Alloys and Compounds 585 (2014): 32-39. https://doi.org/10.1016/i.jallcom.2013.09.131

[14] Boettinger, W. J., U. R. Kattner, K-W. Moon, and J. H. Perepezko. DTA and Heat-flux DSC Measurements of Alloy Melting and Freezing. Washington: National Institute of Standards and Technology, 2006. https://doi.org/10.1016/B978-008044629-5/50005-7

[15] Chellvarajoo, Srivalli, and M. Z. Abdullah. "Microstructure and mechanical properties of Pb-free Sn-3.0 Ag-0.5 Cu solder pastes added with $\mathrm{NiO}$ nanoparticles after reflow soldering process." Materials \& Design 90 (2016): $499-507$. https://doi.org/10.1016/j.matdes.2015.10.142

[16] Chellvarajoo, Srivalli, and M. Z. Abdullah. "Investigation on nano-reinforced solder paste after reflow soldering part 1: Effects of nano-reinforced solder paste on melting, hardness, spreading rate, and wetting quality." Microelectronics Reliability 84 (2018): 230-237. https://doi.org/10.1016/j.microrel.2018.03.027

[17] Chellvarajoo, Srivalli, M. Z. Abdullah, and C. Y. Khor. "Effects of diamond nanoparticles reinforcement into lead-free Sn-3.0 Ag-0.5 Cu solder pastes on microstructure and mechanical properties after reflow soldering process." Materials \& Design 82 (2015): 206-215. https://doi.org/10.1016/j.matdes.2015.05.065

[18] Chen, Guang, Hao Peng, Vadim V. Silberschmidt, Y. C. Chan, Changqing Liu, and Fengshun Wu. "Performance of Sn3.0 Ag-0.5 Cu composite solder with TiC reinforcement: physical properties, solderability and microstructural 
evolution under isothermal ageing." Journal of Alloys and Compounds 685 (2016): 680-689. https://doi.org/10.1016/i.jallcom.2016.05.245

[19] Cheng, Shunfeng, Chien-Ming Huang, and Michael Pecht. "A review of lead-free solders for electronics applications." Microelectronics Reliability 75 (2017): 77-95. https://doi.org/10.1016/i.microrel.2017.06.016

[20] Ding, Min, Wenqing Xing, Xingye Yu, Le Ma, Wei Zuo, and Zhiqiang Ji. "Effect of micro alumina particles additions on the interfacial behavior and mechanical properties of Sn-9Zn-1A/2O3 nanoparticles on low temperature wetting and soldering of 6061 aluminum alloys." Journal of Alloys and Compounds 739 (2018): 481-488. https://doi.org/10.1016/i.jallcom.2017.12.247

[21] Eid, E. A., A. N. Fouda, and El-Shazly M. Duraia. "Effect of adding 0.5 wt\% ZnO nanoparticles, temperature and strain rate on tensile properties of Sn-5.0 wt\% Sb-0.5 wt\% Cu (SSC505) lead free solder alloy." Materials Science and Engineering: A 657 (2016): 104-114. https://doi.org/10.1016/i.msea.2016.01.081

[22] Efzan, Ervina, and A. Marini. "A review of solder evolution in electronic application." International Journal of Engineering 1, no. 1 (2012): 2305-8269.

[23] Noor, Ervina Efzan Mhd, and Amares Singh. "Review on the effect of alloying element and nanoparticle additions on the properties of Sn-Ag-Cu solder alloys." Soldering \& Surface Mount Technology 26, no. 3 (2014): $147-161$. https://doi.org/10.1108/SSMT-02-2014-0001

[24] El-Daly, A. A., T. A. Elmosalami, W. M. Desoky, M. G. El-Shaarawy, and A. M. Abdraboh. "Tensile deformation behavior and melting property of nano-sized ZnO particles reinforced Sn-3.0 Ag-0.5 Cu lead-free solder." Materials Science and Engineering: A 618 (2014): 389-397. https://doi.org/10.1016/i.msea.2014.09.028

[25] Khodabakhshi, F., R. Sayyadi, and N. Shahamat Javid. "Lead free Sn-Ag-Cu solders reinforced by Ni-coated graphene nanosheets prepared by mechanical alloying: Microstructural evolution and mechanical durability." Materials Science and Engineering: A 702 (2017): 371-385. https://doi.org/10.1016/i.msea.2017.07.024

[26] Fathian, Zahra, Ali Maleki, and Behzad Niroumand. "Synthesis and characterization of ceramic nanoparticles reinforced lead-free solder." Ceramics International 43, no. 6 (2017): 5302-5310. https://doi.org/10.1016/i.ceramint.2017.01.067

[27] Fouzder, Tama, Ismathullakhan Shafiq, Y. C. Chan, A. Sharif, and Winco KC Yung. "Influence of SrTiO3 nano-particles on the microstructure and shear strength of Sn-Ag-Cu solder on Au/Ni metallized Cu pads." Journal of Alloys and Compounds 509, no. 5 (2011): 1885-1892. https://doi.org/10.1016/i.jallcom.2010.10.081

[28] Callister, William D., and David G. Rethwisch. Materials Science and Engineering 9th Ed. John Wiley \& Sons Inc., 2007.

[29] Sujan, G. K., A. S. M. A. Haseeb, Hiroshi Nishikawa, and M. A. Amalina. "Interfacial reaction, ball shear strength and fracture surface analysis of lead-free solder joints prepared using cobalt nanoparticle doped flux." Journal of Alloys and Compounds 695 (2017): 981-990. https://doi.org/10.1016/i.jallcom.2016.10.219

[30] Gain, Asit Kumar, Yan Cheong Chan, and Winco KC Yung. "Effect of additions of ZrO2 nano-particles on the microstructure and shear strength of $\mathrm{Sn}-\mathrm{Ag}-\mathrm{Cu}$ solder on $\mathrm{Au} / \mathrm{Ni}$ metallized Cu pads." Microelectronics Reliability 51 , no. 12 (2011): 2306-2313. https://doi.org/10.1016/i.microrel.2011.03.042

[31] Gancarz, Tomasz. "The effect of aging temperature on the phenomena occurring at the interface of solder SnZn with Na on Cu substrate." Materials Letters 171 (2016): 187-190. https://doi.org/10.1016/i.matlet.2016.02.066

[32] Gao, Lili, Songbai Xue, Liang Zhang, Zhong Sheng, Feng Ji, Wei Dai, Sheng-lin Yu, and Guang Zeng. "Effect of alloying elements on properties and microstructures of SnAgCu solders." Microelectronic Engineering 87, no. 11 (2010): 2025-2034. https://doi.org/10.1016/i.mee.2010.04.007

[33] Mohammed, Gh, and S. El-Gamal. "Influence of SiC nanoparticles addition on the microstructure, thermal and tensile properties of Sn-Zn-Ag solder alloy." Materials Research Express 5, no. 8 (2018): 086508. https://doi.org/10.1088/2053-1591/aad25c

[34] Guo, Bingfeng, Anil Kunwar, Ning Zhao, Jun Chen, Yunpeng Wang, and Haitao Ma. "Effect of Ag3Sn nanoparticles and temperature on Cu6Sn5 IMC growth in Sn-xAg/Cu solder joints." Materials Research Bulletin 99 (2018): 239248. https://doi.org/10.1016/j.materresbull.2017.11.022

[35] Zou, H. F., Q. K. Zhang, and Z. F. Zhang. "Interfacial microstructure and mechanical properties of SnBi/Cu joints by alloying Cu substrate." Materials Science and Engineering: A $532 \quad$ (2012): $167-177$. https://doi.org/10.1016/i.msea.2011.10.078

[36] Kotadia, H. R., O. Mokhtari, M. P. Clode, M. A. Green, and S. H. Mannan. "Intermetallic compound growth suppression at high temperature in SAC solders with $\mathrm{Zn}$ addition on $\mathrm{Cu}$ and Ni-P substrates." Journal of Alloys and Compounds 511, no. 1 (2012): 176-188. https://doi.org/10.1016/i.jallcom.2011.09.024

[37] Tsukamoto, H., T. Nishimura, S. Suenaga, Stuart D. McDonald, Keith W. Sweatman, and Kazuhiro Nogita. "The influence of solder composition on the impact strength of lead-free solder ball grid array joints." Microelectronics Reliability 51, no. 3 (2011): 657-667. https://doi.org/10.1016/j.microrel.2010.10.012 
[38] Haseeb, A. S. M. A., M. M. Arafat, and Mohd Rafie Johan. "Stability of molybdenum nanoparticles in Sn-3.8 Ag-0.7 $\mathrm{Cu}$ solder during multiple reflow and their influence on interfacial intermetallic compounds." Materials Characterization 64 (2012): 27-35. https://doi.org/10.1016/i.matchar.2011.11.006

[39] Haseeb, A. S. M. A., and Tay See Leng. "Effects of Co nanoparticle addition to Sn-3.8 Ag-0.7 Cu solder on interfacial structure after reflow and ageing." Intermetallics 19, no. 5 (2011): $707-712$. https://doi.org/10.1016/i.intermet.2011.01.009

[40] Huang, Huizhen, Gewang Shuai, Xiuqin Wei, and Chuanqiang Yin. "Effects of sulfur addition on the wettability and corrosion resistance of Sn-0.7 Cu lead-free solder." Microelectronics Reliability 74 (2017): 15-21. https://doi.org/10.1016/i.microrel.2017.05.010

[41] Hu, Xiao, Sha Xu, Ying Yang, Zhong Chen, and Y. C. Chan. "Effect of TiO2 nanoparticle addition on electroless Ni-P under bump metallization for lead-free solder interconnection." Materials Science and Engineering: A 600 (2014): 67-75. https://doi.org/10.1016/i.msea.2014.02.011

[42] Ichitsubo, Tetsu, Eiichiro Matsubara, Kozo Fujiwara, Masahiko Yamaguchi, Hisao Irie, Seishi Kumamoto, and Takaaki Anada. "Control of compound forming reaction at the interface between SnZn solder and Cu substrate." Journal of Alloys and Compounds 392, no. 1-2 (2005): 200-205. https://doi.org/10.1016/i.jallcom.2004.09.043

[43] Shen, Jun, and Yan Cheong Chan. "Research advances in nano-composite solders." Microelectronics Reliability 49, no. 3 (2009): 223-234. https://doi.org/10.1016/i.microrel.2008.10.004

[44] Shen, Jun, and Yan Cheong Chan. "Effects of ZrO2 nanoparticles on the mechanical properties of Sn-Zn solder joints on $\mathrm{Au} / \mathrm{Ni} / \mathrm{Cu}$ pads." Journal of Alloys and Compounds 477, no. 1-2 (2009): 552-559. https://doi.org/10.1016/i.jallcom.2008.10.140

[45] Li, J. F., S. H. Mannan, M. P. Clode, D. C. Whalley, and D. A. Hutt. "Interfacial reactions between molten Sn-Bi-X solders and $\mathrm{Cu}$ substrates for liquid solder interconnects." Acta Materialia 54, no. 11 (2006): $2907-2922$. https://doi.org/10.1016/i.actamat.2006.02.030

[46] Jung, Do-Hyun, Ashutosh Sharma, and Jae-Pil Jung. "Influence of dual ceramic nanomaterials on the solderability and interfacial reactions between lead-free $\mathrm{Sn}-\mathrm{Ag}-\mathrm{Cu}$ and a $\mathrm{Cu}$ conductor." Journal of Alloys and Compounds 743 (2018): 300-313. https://doi.org/10.1016/i.jallcom.2018.02.017

[47] Mehrabi, K., F. Khodabakhshi, E. Zareh, A. Shahbazkhan, and A. Simchi. "Effect of alumina nanoparticles on the microstructure and mechanical durability of meltspun lead-free solders based on tin alloys." Journal of Alloys and Compounds 688 (2016): 143-155. https://doi.org/10.1016/j.jallcom.2016.06.296

[48] Kanlayasiri, Kannachai, and Nadee Meesathien. "Effects of zinc oxide nanoparticles on properties of SAC0307 leadfree solder paste." Advances in Materials Science and Engineering 2018 (2018): 1-10. https://doi.org/10.1155/2018/3750742

[49] Kanlayasiri, Kannachai, and Kamtorn Sukpimai. "Effects of indium on the intermetallic layer between low-Ag SAC0307-xIn lead-free solders and Cu substrate." Journal of Alloys and Compounds 668 (2016): 169-175. https://doi.org/10.1016/i.jallcom.2016.01.231

[50] Kotadia, Hiren R., Philip D. Howes, and Samjid H. Mannan. "A review: On the development of low melting temperature Pb-free solders." Microelectronics Reliability 54, no. 6-7 (2014): 1253-1273. https://doi.org/10.1016/i.microrel.2014.02.025

[51] Kumar, K. Mohan, V. Kripesh, and Andrew AO Tay. "Single-wall carbon nanotube (SWCNT) functionalized Sn-Ag-Cu lead-free composite solders." Journal of Alloys and Compounds 450, no. 1-2 (2008): $229-237$. https://doi.org/10.1016/i.jallcom.2006.10.123

[52] Kumar, Santosh, Joseph Smetana, David Love, James Watkowski, Richard Parker, and Carol A. Handwerker. "Microvoid formation at solder-copper interfaces during annealing: a systematic study of the root cause." Journal of Electronic Materials 40, no. 12 (2011): 2415. https://doi.org/10.1007/s11664-011-1768-9

[53] Tsao, L. C. "Suppressing effect of 0.5 wt.\% nano-TiO2 addition into Sn-3.5 Ag-0.5 Cu solder alloy on the intermetallic growth with $\mathrm{Cu}$ substrate during isothermal aging." Journal of Alloys and Compounds 509, no. 33 (2011): 8441 8448. https://doi.org/10.1016/j.jallcom.2011.05.116

[54] Tsao, L. C., C. H. Huang, C. H. Chung, and R. S. Chen. "Influence of TiO2 nanoparticles addition on the microstructural and mechanical properties of Sn0. 7Cu nano-composite solder." Materials Science and Engineering: A 545 (2012): 194-200. https://doi.org/10.1016/i.msea.2012.03.025

[55] Tsao, L. C., S. Y. Chang, C. I. Lee, W. H. Sun, and C. H. Huang. "Effects of nano-Al2O3 additions on microstructure development and hardness of Sn3. 5Ag0. 5Cu solder." Materials \& Design 31, no. 10 (2010): 4831-4835. https://doi.org/10.1016/i.matdes.2010.04.033

[56] Liu, Jian-Chun, Gong Zhang, Zheng-Hong Wang, Ju-Sheng Ma, and Katsuaki Suganuma. "Thermal property, wettability and interfacial characterization of novel $\mathrm{Sn}-\mathrm{Zn}$-Bi-In alloys as low-temperature lead-free solders." Materials \& Design 84 (2015): 331-339. https://doi.org/10.1016/j.matdes.2015.06.148 
[57] Liu, Ping, Pei Yao, and Jim Liu. "Effects of multiple reflows on interfacial reaction and shear strength of SnAgCu and $\mathrm{SnPb}$ solder joints with different PCB surface finishes." Journal of Alloys and Compounds 470, no. 1-2 (2009): 188194. https://doi.org/10.1016/i.jallcom.2008.02.102

[58] Li, Z. L., G. Y. Li, B. Li, L. X. Cheng, J. H. Huang, and Y. Tang. "Size effect on IMC growth in micro-scale Sn-3.0 Ag-0.5 Cu-0.1 TiO2 solder joints in reflow process." Journal of Alloys and Compounds 685 (2016): 983-991. https://doi.org/10.1016/i.jallcom.2016.06.295

[59] Luo, Tingbi, Anmin Hu, Jing Hu, Ming Li, and Dali Mao. "Microstructure and mechanical properties of Sn-Zn-Bi-Cr lead-free solder." Microelectronics Reliability $52, \quad$ no. $3 \quad$ (2012): $585-588$. https://doi.org/10.1016/i.microrel.2011.10.005

[60] Lu, Yu, Le Ma, Shu-yong Li, Wei Zuo, Zhi-qiang Ji, and Min Ding. "Effect of Cu element addition on the interfacial behavior and mechanical properties of Sn9Zn-1Al2O3 soldering 6061 aluminum alloys: First-principle calculations and experimental research." Journal of Alloys and Compounds 765 (2018): 128-139. https://doi.org/10.1016/j.jallcom.2018.06.178

[61] Ma, Dong-liang, and Ping Wu. "Effects of Zn addition on mechanical properties of eutectic Sn-58Bi solder during liquid-state aging." Transactions of Nonferrous Metals Society of China 25, no. 4 (2015): 1225-1233. https://doi.org/10.1016/S1003-6326(15)63719-0

[62] Miao, Hui-Wei, and Jenq-Gong Duh. "Microstructure evolution in Sn-Bi and Sn-Bi-Cu solder joints under thermal aging." Materials Chemistry and Physics 71, no. 3 (2001): 255-271. https://doi.org/10.1016/S0254-0584(01)00298$\underline{X}$

[63] MAA, Mohd Salleh, AM Mustafa Al Bakri, H. Kamarudin, M. Bnhussain, and Flora Somidin. "Solderability of Sn-0.7 Cu/Si3N4 lead-free composite solder on Cu-substrate." Physics Procedia 22 (2011): 299-304. https://doi.org/10.1016/i.phpro.2011.11.047

[64] Salleh, MAA Mohd, AM Mustafa Al Bakri, M. H. Zan, Flora Somidin, Noor Farhani Mohd Alui, and Zainal Arifin Ahmad. "Mechanical properties of $\mathrm{Sn}-0.7 \mathrm{Cu} / \mathrm{Si} 3 \mathrm{~N} 4$ lead-free composite solder." Materials Science and Engineering: A 556 (2012): 633-637. https://doi.org/10.1016/i.msea.2012.07.039

[65] Islam, Sheik Md Kazi Nazrul, Ahmed Sharif, and T. Alam. "Interfacial Microstructure, Microhardness and Tensile Properties of Al Micro-Particle Doped Sn-9Zn Eutectic Pb-Free Solder Alloy for Microelectronics Applications." Journal of Telecommunication, Electronic and Computer Engineering (JTEC) 4, no. 2 (2012): 35-39.

[66] Ren, Guang, lan J. Wilding, and Maurice N. Collins. "Alloying influences on low melt temperature SnZn and SnBi solder alloys for electronic interconnections." Journal of Alloys and Compounds 665 (2016): 251-260. https://doi.org/10.1016/j.jallcom.2016.01.006

[67] Ren, Guang, and Maurice N. Collins. "On the mechanism of Sn tunnelling induced intermetallic formation between Sn-8Zn-3Bi solder alloys and Cu substrates." Journal of Alloys and Compounds 791 (2019): 559-566. https://doi.org/10.1016/j.jallcom.2019.03.244

[68] Tay, S. L., A. S. M. A. Haseeb, Mohd Rafie Johan, P. R. Munroe, and Md Zakaria Quadir. "Influence of Ni nanoparticle on the morphology and growth of interfacial intermetallic compounds between Sn-3.8 Ag-0.7 Cu lead-free solder and copper substrate." Intermetallics 33 (2013): 8-15. https://doi.org/10.1016/j.intermet.2012.09.016

[69] Chang, S. Y., C. C. Jain, T. H. Chuang, L. P. Feng, and L. C. Tsao. "Effect of addition of TiO2 nanoparticles on the microstructure, microhardness and interfacial reactions of Sn3. 5AgXCu solder." Materials \& Design 32, no. 10 (2011): 4720-4727. https://doi.org/10.1016/i.matdes.2011.06.044

[70] Shen, Jun, and Yan Cheong Chan. "Effect of metal/ceramic nanoparticle-doped fluxes on the wettability between Sn-Ag-Cu solder and a Cu layer." Journal of Alloys and Compounds 477, no. 1-2 (2009): 909-914. https://doi.org/10.1016/i.jallcom.2008.11.015

[71] Shen, Lu, Asta Qili Foo, Shijie Wang, and Zhong Chen. "Enhancing creep resistance of SnBi solder alloy with nonreactive nano fillers: A study using nanoindentation." Journal of Alloys and Compounds 729 (2017): 498-506. https://doi.org/10.1016/j.jallcom.2017.09.177

[72] Shin, Yue-Seon, Sehyung Lee, Sehoon Yoo, and Chang-Woo Lee. "Mechanical and microstructural properties of SiCmixed Sn-Bi composite solder bumps by electroplating." In 2009 European Microelectronics and Packaging Conference, pp. 1-4. IEEE, 2009.

[73] Amares, Singh, Durairaj Rajkumar, Mhd Noor Ervina Efzan, and Woong Sia Way. "Reliability Study of Lead Free Sn3.8 Ag-0.7 Cu and Copper (Cu) Substrate based on the Microstructure, Physical and Mechanical Properties." Journal of Mechanical Engineering 5, no. 2 (2018): 169-180.

[74] Yang, T. L., J. Y. Wu, C. C. Li, S. Yang, and C. R. Kao. "Low temperature bonding for high temperature applications by using SnBi solders." Journal of Alloys and Compounds 647 (2015): $681-685$. https://doi.org/10.1016/i.jallcom.2015.05.249 
[75] Tan, Ai Ting, Ai Wen Tan, and Farazila Yusof. "Influence of nanoparticle addition on the formation and growth of intermetallic compounds (IMCs) in $\mathrm{Cu} / \mathrm{Sn}-\mathrm{Ag}-\mathrm{Cu} / \mathrm{Cu}$ solder joint during different thermal conditions." Science and Technology of Advanced Materials 16, no. 3 (2015): 033505. https://doi.org/10.1088/1468-6996/16/3/033505

[76] Tang, Y., G. Y. Li, and Y. C. Pan. "Effects of TiO2 nanoparticles addition on microstructure, microhardness and tensile properties of Sn-3.0 Ag-0.5 Cu-xTiO2 composite solder." Materials \& Design 55 (2014): 574-582. https://doi.org/10.1016/i.matdes.2013.10.033

[77] Vuorinen, V., H. Yu, T. Laurila, and J. K. Kivilahti. "Formation of intermetallic compounds between liquid Sn and various CuNi x metallizations." Journal of Electronic Materials 37, no. 6 (2008): $792-805$. https://doi.org/10.1007/s11664-008-0411-x

[78] Chen, W. M., S. K. Kang, and C. R. Kao. "Effects of Ti addition to Sn-Ag and Sn-Cu solders." Journal of Alloys and Compounds 520 (2012): 244-249. https://doi.org/10.1016/i.jallcom.2012.01.032

[79] Wang, Fengjiang, Ying Huang, and Chengchao Du. "Mechanical properties of SnBi-SnAgCu composition mixed solder joints using bending test." Materials Science and Engineering: A 668 (2016): $224-233$. https://doi.org/10.1016/j.msea.2016.05.072

[80] Wang, Shaobin, and Yao Yao. "Size effect of Sn3. OAg0. 5Cu solder joint on intermetallic layer growth." In 2017 18th International Conference on Electronic Packaging Technology (ICEPT), pp. 1547-1551. IEEE, 2017. https://doi.org/10.1109/ICEPT.2017.8046730

[81] Wang, Yaoli, Guangxin Wang, Kexing Song, and Keke Zhang. "Effect of Ni addition on the wettability and microstructure of Sn2. 5Ag0. 7Cu0. 1RE solder alloy." Materials \& Design 119 (2017): $219-224$. https://doi.org/10.1016/i.matdes.2017.01.046

[82] Wattanakornphaiboon, Anattiya, Rungsinee Canyook, and Kittichai Fakpan. "Effect of SnO2 reinforcement on creep property of Sn-Ag-Cu solders." Materials Today: Proceedings 5, no. 3 (2018): 9213-9219. https://doi.org/10.1016/j.matpr.2017.10.092

[83] Chen, Wenxue, Songbai Xue, Hui Wang, and Yuhua Hu. "Effects of Ag on properties of Sn-9Zn lead-free solder." Rare Metal Materials and Engineering 39, no. 10 (2010): 1702-1706. https://doi.org/10.1016/S1875$\underline{5372(10) 60127-0}$

[84] Xing, Wen-qing, Xin-ye Yu, Heng Li, Le Ma, Wei Zuo, Peng Dong, Wen-xian Wang, and Min Ding. "Effect of nano Al2O3 additions on the interfacial behavior and mechanical properties of eutectic Sn-9Zn solder on low temperature wetting and soldering of 6061 aluminum alloys." Journal of Alloys and Compounds 695 (2017): $574-$ 582. https://doi.org/10.1016/i.jallcom.2016.11.136

[85] Xu, Lianyong, Xi Chen, Hongyang Jing, Lixia Wang, Jun Wei, and Yongdian Han. "Design and performance of Ag nanoparticle-modified graphene/SnAgCu lead-free solders." Materials Science and Engineering: A 667 (2016): $87-$ 96. https://doi.org/10.1016/i.msea.2016.04.084

[86] Xu, Sha, Yan Cheong Chan, Kaili Zhang, and K. C. Yung. "Interfacial intermetallic growth and mechanical properties of carbon nanotubes reinforced $\mathrm{Sn} 3$. 5Ag0. 5Cu solder joint under current stressing." Journal of Alloys and Compounds 595 (2014): 92-102. https://doi.org/10.1016/i.jallcom.2014.01.083

[87] Tang, Y., S. M. Luo, W. F. Huang, Y. C. Pan, and G. Y. Li. "Effects of Mn nanoparticles on tensile properties of low-Ag Sn-0.3 Ag-0.7 Cu-xMn solder alloys and joints." Journal of Alloys and Compounds 719 (2017): 365-375. https://doi.org/10.1016/i.jallcom.2017.05.182

[88] Yahaya, Muhamad Zamri, Fakhrozi Che Ani, Zambri Samsudin, Salim Sahin, Mohd Zulkifly Abdullah, and Ahmad Azmin Mohamad. "Hardness profiles of Sn-3.0 Ag-0.5 Cu-TiO2 composite solder by nanoindentation." Materials Science and Engineering: A 669 (2016): 178-186. https://doi.org/10.1016/i.msea.2016.05.081

[89] Yang, Lizhuang, Wei Zhou, Yinghua Liang, Wenquan Cui, and Ping Wu. "Improved microstructure and mechanical properties for Sn58Bi solder alloy by addition of Ni-coated carbon nanotubes." Materials Science and Engineering: A 642 (2015): 7-15. https://doi.org/10.1016/i.msea.2015.06.080

[90] Yang, Li, Lu Zhu, Yaocheng Zhang, Shiyuan Zhou, Guoqiang Wang, Sai Shen, and Xiaolong Shi. "Microstructure, IMCs layer and reliability of $\mathrm{Sn}-58 \mathrm{Bi}$ solder joint reinforced by Mo nanoparticles during thermal cycling." Materials Characterization 148 (2019): 280-291. https://doi.org/10.1016/i.matchar.2018.12.012

[91] Yoon, Jeong-Won, and Seung-Boo Jung. "Reliability studies of Sn-9Zn/Cu solder joints with aging treatment." Journal of Alloys and Compounds 407, no. 1-2 (2006): 141-149. https://doi.org/10.1016/i.jallcom.2005.06.047

[92] Li, Z. L., G. Y. Li, B. Li, L. X. Cheng, J. H. Huang, and Y. Tang. "Size effect on IMC growth in micro-scale Sn-3.0 Ag-0.5 Cu-0.1 TiO2 solder joints in reflow process." Journal of Alloys and Compounds 685 (2016): 983-991. https://doi.org/10.1016/i.jallcom.2016.06.295

[93] Zhang, Liang, Cheng-wen He, Yong-huan Guo, Ji-guang Han, Yong-wei Zhang, and Xu-yan Wang. "Development of SnAg-based lead free solders in electronics packaging." Microelectronics Reliability 52, no. 3 (2012): 559-578. https://doi.org/10.1016/i.microrel.2011.10.006 
[94] Zhang, Liang, and King-Ning Tu. "Structure and properties of lead-free solders bearing micro and nano particles." Materials Science and Engineering: R: Reports 82 (2014): 1-32. https://doi.org/10.1016/j.mser.2014.06.001

[95] Zhu, Ze, Yan-Cheong Chan, Zhong Chen, Chee-Lip Gan, and Fengshun Wu. "Effect of the size of carbon nanotubes (CNTs) on the microstructure and mechanical strength of CNTs-doped composite Sn0. 3Ag0. 7Cu-CNTs solder." Materials Science and Engineering: A 727 (2018): 160-169. https://doi.org/10.1016/i.msea.2018.05.002

[96] Zou, Changdong, Yulai Gao, Bin Yang, and Qijie Zhai. "Melting and solidification properties of the nanoparticles of Sn3. OAg0. 5Cu lead-free solder alloy." Materials Characterization 61, no. 4 (2010): $474-480$. https://doi.org/10.1016/i.matchar.2010.02.004 